\title{
Técnicas de poder, disciplinas do olhar: aspectos da construção do "jornalismo moderno" no Brasil
}

Flávia Biroli*

\begin{abstract}
Resumo:
Este artigo trata da correlação entre as transformações ocorridas no jornalismo a partir de meados do século XX e a configuração do profissional do jornalismo como trabalhador produtivo, disciplinado, normatizado. Seu foco é a análise de um conjunto de discursos, produzidos a partir da década de 1940, no Brasil, que convergem em dispositivos de disciplinamento do olhar e da escrita, em técnicas de disposição do tempo, da experiência e dos corpos - dos jornalistas e dos seus leitores.
\end{abstract}

Palavras-chave: jornalismo, disciplina, norma.

Este artigo trata da configuração do profissional do jornalismo como trabalhador produtivo, disciplinado e normatizado, por meio da análise de textos diversos escritos por jornalistas a partir da década de 1940 e de manuais de redação.

A configuração do "profissional moderno" ao longo das décadas de 1950, 1960 e 1970, especialmente, observada pelo ângulo da normatização, aparece aqui vinculada às transformações ocorridas no jornalismo no Brasil. Estas últimas, por sua vez, estão ligadas às transformações pelas quais passaram os meios de comunicação durante o século XX, na medida em que se estruturavam como empresas lucrativas, ampliavam seu público e, posteriormente, organizavam-se para competir ou sobreviver em um mercado em que a televisão figuraria como a grande vedete em termos de público e de lucratividade. Uma de suas facetas, no caso brasileiro, é a forma tomada pela adoção do modelo norte-americano de jornalismo e a substituição do jornalismo caracterizado como de opinião, de combate ou literário pelo jornalismo caracterizado como isento, empresarial, moderno - termos que variam entre os diferentes autores que tratam do assunto, mas que compõem um conjunto relativamente homogêneo de oposições que estruturam as visões predominantes em relação ao "novo jornalismo" que se configura ao longo do século XX.

A análise de uma série de textos escritos a partir da década de 1940 compêndios de normas, manuais de redação, estudos sobre as mudanças no jornalismo brasileiro, ensaios escritos por jornalistas sobre a profissão etc. - permite a indicação de 
aspectos relevantes da normatização no jornalismo, composta por técnicas de organização do trabalho e de constituição do jornalista como trabalhador produtivo adequado aos "novos tempos". São analisadas imagens e percepções correntes nas fontes pesquisadas, que constituem, segundo a hipótese trabalhada, um campo discursivo comum que converge em dispositivos de disciplinamento do olhar e da escrita dos jornalistas.

Destaca-se que, neste artigo, não se pretende explicar as causas dessas transformações nem descrever ou analisar o contexto em que se deram, mas levantar aspectos relevantes do modo como foram entendidas nos textos que constituem as fontes da pesquisa que dá origem a este artigo ${ }^{1}$.

Três imagens organizam o artigo: a da fábrica trepidante de notícias, a do jornalista 24 horas e a do jornalismo crítico desprovido de autores. Por meio delas, discuto as relações entre disciplina, tempo de trabalho e tempo de vida; disciplina e constituição de sujeitos produtivos; disciplina, normas para a escrita e a noção de objetividade no jornalismo, sempre a partir das imagens e percepções correntes nos textos pesquisados.

A constituição do "jornalismo moderno" e do "novo jornalista" pode ser relacionada, como se disse, a transformações no mercado jornalístico, a transformações técnicas que fizeram parte da reorganização do trabalho nas redações, aos primeiros cursos de jornalismo e a um saber sobre jornais e jornalistas fundado na observação da rotina de trabalho, visando o aumento da produtividade, assim como a maior influência do chamado modelo norte-americano de jornalismo, que tem uma inserção específica na prática dos jornais e jornalistas brasileiros. Em conjunto, essas transformações, saberes e modelos constituiriam um conjunto renovado de referenciais para o julgamento, a distinção entre os profissionais e os produtos de seu trabalho e a valorização de condutas.

Michael Schudson, ao discutir a configuração da norma da objetividade como central ao jornalismo nos Estados Unidos, sobretudo a partir da década de 1920, destaca que a adoção de normas de caráter moral, como entende a norma da objetividade, tem ao menos dois eixos explicativos possíveis. Um deles, de caráter durkheimiano, diria respeito à constituição de normas sociais compartilhadas por meio das quais o grupo se identifica e legitima suas práticas. Outro, de caráter weberiano, ressaltaria o controle hierárquico, o caráter disciplinador das normas. Assim, a necessidade de coesão social (Durkheim) e a necessidade de controle social (Weber) definiriam sua articulação ${ }^{2}$. 
A discussão que segue destaca o caráter disciplinador das imagens e percepções presentes nos textos escritos por jornalistas e, de maneira mais explícita, nos manuais de redação. O ponto principal é que, aqui, a configuração de uma identidade renovada é inseparável dos dispositivos disciplinares que constituem o "novo jornalista". Assim, os elementos que permitem o compartilhamento de referências e valores entre os jornalistas (incluídos aí recursos para sua valorização profissional) e as formas de controle e disciplinamento a eles relacionadas (incluídos aí os recursos das empresas para um funcionamento empresarial mais controlado e lucrativo) constituem, em conjunto, as configurações do "jornalista moderno" presentes nos discursos analisados.

\section{Progresso das sociedades, gênese dos indivíduos}

Antes de passar a observações e análises no campo de uma história da imprensa e do jornalismo no Brasil, explicito o percurso teórico e o sentido de noções que são aqui utilizadas: controle, disciplinamento, normatização.

O subtítulo que abre esta parte do artigo foi extraído da obra Vigiar e Punir, de Michel Foucault, e compõe observações sobre técnicas de disciplinamento que foram, sobretudo a partir do século XVIII, centrais à constituição da individualidade no capitalismo industrial. A análise observa técnicas que constituíram indivíduos produtivos, por meio de dispositivos de uma microfísica do poder que dispõe do tempo e dos corpos de uma maneira diferenciada do modo pelo qual outras formas de organização social o fizeram. Tratam-se, segundo o autor, de dispositivos que tornam o corpo "tanto mais obediente quanto é mais útil, e inversamente"3.

Em um outro texto de sua autoria, A vida dos homens infames, Foucault faz uma referência breve à correlação entre as técnicas do disciplinamento individualizante e a constituição de um discurso-esquadrinhamento de novo tipo, voltado para o cotidiano. A partir da análise de textos produzidos na França entre os séculos XVII e XVIII, provenientes dos arquivos de reclusão, da polícia, das petições ao rei e das lettres de cachet, o autor observa um cruzamento peculiar entre mecanismos políticos e efeitos de discurso ${ }^{4}$; transpondo-se do olhar cristão aos mecanismos modernos de administração dos homens, as faltas e vênias cotidianas saltariam do segredar ritmado das confissões para um esquadrinhamento que se acumularia sob a forma de traços escritos.

As duas obras citadas tratam de acontecimentos semelhantes, que convergem em formas de individuação. São, porém, flagrados em discursos variados e em áreas de 
intervenção diferenciadas. Como afirma o autor, a "anatomia política" disciplinar de que trata consiste em uma multiplicidade de processos mínimos, "de origens diferentes, de localizações esparsas, que se recordam, se repetem, ou se imitam, apóiam-se uns sobre os outros, distinguem-se segundo seu campo de aplicação, entram em convergência e esboçam aos poucos a fachada de um método geral" ${ }^{\prime 5}$. Em conjunto, comporiam a técnica e o enfoque do detalhe, dos esmiuçamentos de que teria nascido o humanismo moderno.

Podemos relacionar os dois estudos para encontrar um caminho de reflexão sobre os cruzamentos entre a produção de corpos disciplinados e dóceis e a produção de um olhar sobre o cotidiano que o torna um tempo-espaço habitado por acontecimentos e individualidades conhecidos, dominados, utilizados. Há, nesse sentido, algumas indicações do autor sobre a organização de formas de controle sobre os indivíduos e suas experiências pelo jornalismo e pela publicidade, nas sociedades contemporâneas. Indicações breves, mencionadas abaixo.

Em $A$ vida dos homens infames, Foucault afirma que as técnicas observadas, nas quais o esquadrinhamento se constitui do olhar do monarca e da assimetria existente entre este e seus súditos, passariam, paulatinamente, a ser constituídas por uma "rede fina” feita das instituições da justiça, da psiquiatria, da medicina, da política. A determinação recíproca de sentidos entre o corpo do miserável e o olhar requisitado do rei, entre as "desordens que se querem dizer" e o "rigor das formas que é preciso seguir", seria substituída, inclusive em sua intensidade, por homens e objetos transformados em "processos, atualidades de jornal, casos"; seria substituída por um discurso sobre o cotidiano que analisaria o banal "de acordo com a grelha eficaz mas cinzenta da administração, do jornalismo e da ciência"6.

Em uma conferência na qual trata, como em Vigiar e Punir, do panoptismo como metáfora para as formas de controle e disciplinamento que se organizam na modernidade, Foucault fala em técnicas de controle do tempo dos homens que teriam composto, a partir do século XIX, uma série de instituições (fábricas, instituições pedagógicas, carcerárias e também caixas econômicas e de assistência). Tratava-se de dispor do tempo de vida dos homens, de sua existência, oferecendo esse tempo ao aparelho de produção. Controle geral do tempo que passaria, com o avanço da industrialização, a ser exercido "pelo mecanismo do consumo e da publicidade"7. 
As referências ao jornalismo ou ao consumo e à publicidade são, como foi dito, breves. São também bastante amplas. Indicam, no entanto, caminhos para a reflexão e a análise.

As transformações ocorridas no jornalismo a partir de meados do século XX, discutidas a seguir a partir de sua configuração nos textos analisados, têm como um dos seus aspectos técnicas e dispositivos que teriam como efeito potencial o disciplinamento de corpos e olhares. São, portanto, no sentido que nos indica Foucault, parte de mecanismos mais amplos que constituem um modo de esquadrinhamento do cotidiano que implica em técnicas de disposição do tempo, da experiência e dos corpos - no caso de que tratamos, dos jornalistas e dos seus leitores. Teríamos, nesse caso, um efeito específico da correlação feita por Foucault entre o progresso das sociedades e a gênese dos indivíduos, produzindo, entre outras coisas, o próprio jornalista moderno como figuração subjetiva-profissional de um olhar disciplinado e de um conjunto de discursos dispersos (mas não desordenados) que constitui a realidade cotidiana, o tempo do cotidiano, que nas sociedades contemporâneas confunde-se com o ritmo dos fluxos de informação, distribuídos e acessados desigualmente.

No que se refere especificamente aos jornalistas, os dispositivos de disciplinamento parecem ser definidores das rotinas de trabalho e, em sentido mais amplo, de sua subjetividade. Ambas, rotinas de trabalho e percepções subjetivas, constituem-se reciprocamente (não há limites claros ou demarcáveis entre uma e outra) e são, por sua vez, definidoras do olhar e da escrita dos trabalhadores do jornalismo.

No caso brasileiro, desde que não se pense em uma linha evolutiva homogênea e contínua, a profissionalização/normatização em curso no Brasil dos anos 1940-60 pode ser entendida como a origem dos padrões predominantes no jornalismo na segunda metade do século XX, sobretudo a partir de meados da década de 1970. Esses padrões, materializados fortemente no modelo de jornalismo adotado pela Folha de S.Paulo, foram inicialmente marcados pela influência da televisão e, mais recentemente, da internet, sobre as rotinas produtivas e sobre as formas de apresentação do jornalismo impresso. Foram marcados, ainda, por formas de controle e cerceamento internas e externas às redações, vigentes durante a ditadura militar instaurada em $1964^{8}$ e por uma série de estratégias difusas e duradouras para a produção do tipo de profissional a elas adequado, presentes na formação dos profissionais nas universidades ou nas redações ${ }^{9}$, nas formas de seleção e separação entre os mais e os menos habilidosos, no modo de composição das hierarquias e do status na profissão. 
Se houve mudanças, é preciso lembrar que não há "progresso" sem a gênese de indivíduos que trabalhem adequadamente para a reprodução de sua lógica, integrem e internalizem essa lógica e, sobretudo, a defendam. Daí a impossibilidade de separar controle, disciplina e construção de identidade, mesmo quando se pensa nas formas de distinção e valorização que constituem as normas abordadas.

Os discursos analisados a seguir são considerados, aqui, parte dessa gênese. $\mathrm{Na}$ medida em que valorizam e naturalizam práticas, ações e percepções é que constituem seus objetos: o "jornalismo moderno" e os trabalhadores a ele adequados.

\section{A fábrica trepidante de notícias}

As mudanças pelas quais passou a imprensa brasileira durante meados do século XX, sobretudo a partir da década de 1940, foram percebidas amplamente como integradas a um processo de modernização das sociedades. Foram valorizadas na medida em que consistiam em modernização, adequação "aos tempos". Um dos aspectos que atariam a mudança na rotina jornalística a mudanças mais amplas, justificando as adaptações nas rotinas de trabalho, foi a percepção de que estava em curso uma espécie de aceleração do tempo, que implicava em uma correlação de novo tipo entre o cotidiano e a informação, entre as possibilidades dos leitores e aquilo que os jornais noticiosos deveriam oferecer-lhes.

Nas palavras do jornalista e professor de jornalismo Danton Jobim, a informação se transformava em um artigo servido às pressas. O leitor da década de 1950 teria outras exigências, se comparado ao leitor do período anterior à Primeira Guerra, que serve à demarcação cronológica feita por Jobim. O primeiro, simbolizado no habitante de uma grande cidade, que "vive pouco em casa", não deixaria de lado "o momento de intimidade com o seu jornal", mas veria diminuída a qualidade de sua leitura - "leitor apressado, que não pode deter-se muito a meditar, durante a leitura, sobre o significado do que lê". Enquanto isso, a imagem daquele primeiro leitor é, para o jornalista, a de sua avó "sentada numa cadeira de balanço e lendo o Correio Paulistano e $O$ Estado de $S$. Paulo, desde a primeira página até a 'página dos anúncios', que era a última"10.

Décadas depois, esse fator ainda seria retomado e considerado um elemento central à regulação da produção jornalística: de um lado, seria cada vez mais "natural" a necessidade de textos curtos devido ao pouco tempo que os leitores teriam para dedicar ao noticiário escrito, assim como a síntese de informações em tabelas e gráficos, sempre 
que possível; de outro, acentuar-se-ia a necessidade de racionalização do trabalho para economizar tempo. Este último aspecto se fortaleceria nas normas de redação mais recentes, tendo sido menos explícito nos anos 1940 e 50. Normas do jornal O Estado de S. Paulo, presentes em um compêndio editado em 1972, trazem, sob a rubrica "Rapidez", a seguinte observação:

\begin{abstract}
De nada valerá a melhor das informações se não for rapidamente transformada em notícia, com a mínima perda de tempo possível. A cada minuto perdido das fases de coleta, ordenação, preparação e titulação, corresponderá um atraso nas operações de composição, revisão, remessa e distribuição, com graves prejuízos para o processo geral. Este é facilitado pela rapidez, que permite antecipar o fechamento da edição e garante uma disponibilidade de tempo útil para que a redação funcione com a devida flexibilidade em situações de emergência. ${ }^{11}$
\end{abstract}

Nessa perspectiva, a rapidez na coleta e redação da notícia constituiria uma das principais habilidades do jornalista, ao lado da capacidade de síntese e concisão: economia de tempo e de espaço caminham juntas e constituem parte central da rotina produtiva. Além disso, o noticiário televisivo e, mais tarde, a internet, aliados à suposição de que ao leitor interessa o texto rápido, a leitura sem demora e a informação em "tempo real" (mesmo que pontual e repetitiva, se tomada em outra ótica) complementam a justificativa relativa à economia do tempo nas redações.

Em muitos textos escritos por jornalistas e estudiosos do jornalismo entre a década de 1940 e os dias atuais, analisados em busca de percepções e julgamentos sobre as transformações ocorridas no jornalismo brasileiro durante o século XX, a aceleração - do tempo de leitura e de produção da notícia - aparece como um dado das transformações socioeconômicas, muitas vezes apresentadas sob uma noção naturalizada e pouco densa, em termos interpretativos, de progresso técnico.

Em argumento bastante encontrado em estudos sobre o jornalismo brasileiro de meados do século XX, Juarez Bahia associaria a modernização das cidades e o aumento de suas "áreas saneadas" à entrada do jornalismo "numa faixa de operação industrial", que envolveria a substituição gradual dos “jornalistas boêmios" pelos "jornalistas profissionais". O progresso da imprensa refletiria o progresso do país, em uma percepção marcada pelas noções de desenvolvimento e progresso que caracterizam muitos dos olhares para a década de 1950 e, em especial, para o período em que Juscelino Kubitschek governou o país (1956-60) ${ }^{12}$.

Mesmo análises bastante críticas em relação ao jornalismo são, muitas vezes, marcadas por uma espécie de euforia no tratamento das transformações ocorridas 
durante o século XX. A seguinte descrição, feita por Cremilda Medina em estudo publicado em 1978, é um exemplo do que acabo de dizer:

\begin{abstract}
As transformações vividas no Rio de Janeiro na virada do século e, a seguir, o impacto de uma Guerra Mundial e a invenção do rádio, vieram abrir espaço para um novo conteúdo jornalístico atual, universal e com significação imediatamente referida a uma massa em formação. A pressa em ficar sabendo o que ocorre em todo o país, no mundo, começa a tomar corpo e cria um universo de leitores até então inexistente. A notícia empurra a opinião de grande parte das páginas dos jornais; a necessidade de a cada dia conseguir levantar um novo mar de novidades, via telegrama, vai montar a manifestação-núcleo do jornal-notícia. Internacionalmente formamse as agências de notícias, o telégrafo encurta distâncias, o rádio dá informações "em cima da hora" ... 13
\end{abstract}

A correlação entre alguns dos termos que compõem a apreciação da autora permanece, na maior parte das vezes, intocada. Refiro-me à correlação entre a aceleração do tempo, o atual e o universal, mas refiro-me, sobretudo, aos efeitos das rotinas de trabalho recompostas sobre a definição do "jornalista adequado" ou do "jornalista moderno", que teria bilhete de entrada para os novos tempos.

Progresso e aceleração do tempo, vistos como coincidentes, vão se afirmando em seu valor positivo e conferindo novos sentidos à própria atividade jornalística, na qual a competência passaria a ser, cada vez mais, medida pela rapidez com que são executadas as tarefas e pela adaptação do profissional à periodicidade e aos horários de "fechamento" do veículo em que trabalha. Trata-se, nesse caso, não da velocidade de realização do trabalho como variável independente, mas da adequação às rotinas de trabalho, com os critérios de seleção, valorização e percepção do cotidiano que implicam.

O jornalista Alberto Dines, bastante ativo na profissão já no final dos anos 1950 e início dos 60, quando ocupou cargos de chefia durante as reformulações dos jornais cariocas Diário da Noite (1960 e 1961) e, posteriormente, Jornal do Brasil (a partir de 1962, até os anos 1970), caminha em um sentido semelhante ao descrever a relação entre o trabalho jornalístico e o tempo de sua execução e consumo, em estudo publicado pela primeira vez em 1974. Sua reflexão se desdobra em imagens que vinculam as características do fazer jornal às percepções e modos de existência do jornalista, por meio das noções de tempo e velocidade.

"O jornalista trabalha com rapidez para completar cada edição, mas aquela edição se completa com as seguintes até o infinito. Esta noção do tempo distendido, intercalada com o tempo sincopado, faz parte do comportamento físico e psíquico do jornalista”, diz. Para ele, o jornalista deve incorporar a noção temporal fornecida pela 
periodicidade do veículo em que trabalha. Isso significaria desde uma assimilação do tempo de transformação do cotidiano em material noticiável e composição do noticiário na página, até uma projeção do tempo em que a notícia se efetiva e se completa, ao ser percorrida pelo leitor. Mas, mais do que isso, significaria também uma assimilação entre o tempo da notícia tal como é imposto pelo veículo (diferente em diários, semanários etc.) e a vivência do tempo pelo homem de jornal ${ }^{14}$.

A formulação de Dines, assim como as que foram antes citadas, parece-me pertencente a um conjunto de discursos comuns, antes, nos anos 1940 e 50, entre os quais destaco a seguinte formulação, que forneceu o título desta parte do artigo:

Nesta fábrica trepidante que se tornou um grande diário, onde turbilhonam rumores, notícias, informações muitas vezes confusas e descontroladas que trazem sem cessar repórteres, agências, ciclistas e teletipistas, com o vaivém de visitas e os incessantes chamados telefônicos, o jornalista, qualquer que seja seu humor ou sua fadiga, executa um trabalho esgotante. E quando, acabada a sua noite, atravessa a cidade adormecida em busca de um tardio sono, seu espírito tenso evoca já o número do dia seguinte e a matéria que deverá escrever ${ }^{15}$.

A imagem da fábrica trepidante e os enunciados a ela associados parecem ser característicos de certo assombro em relação à intensificação cada vez maior do período de trabalho, em uma atividade na qual a exploração intensiva do trabalho se sobrepôs, cada vez mais, à extensiva, com a justificativa, muitas vezes fornecida pelos próprios jornalistas, de que os fatos não cessam de ocorrer, de que o cotidiano é acelerado e provocaria, ele mesmo, em ritmo alucinante, uma suposta necessidade de reportar à qual corresponderia a necessidade de informar-se dos cidadãos nas sociedades contemporâneas. Vale lembrar que essas necessidades, em última instância, legitimam a centralidade do jornalismo na contemporaneidade, mesmo quando aquilo que é reportado pode não significar, de fato, informação valorosa ou que permita debates de interesse de indivíduos e grupos.

É importante indicar que esse assombro dificilmente se transformou em crítica nas fontes pesquisadas. A convivência entre a concepção do tempo progressivo e acelerado, necessária aos objetivos da produção industrial capitalista (isto é, aos objetivos de manutenção e ampliação do sistema), e a formulação de identidades para o jornalismo, visto como em processo de transformação, não significou, predominantemente, a crítica ou discussão dos efeitos das mudanças no processo de trabalho sobre os jornalistas, sobre o conteúdo produzido e sobre os próprios leitores. 
Se, neste artigo, parto da reflexão de Michel Foucault sobre as técnicas de disposição dos corpos e do tempo dos indivíduos, é importante destacar que a crítica marxista também aponta claramente, nessas alterações na vivência do tempo, uma relação estrutural com a expansão do capitalismo. No século XIX, referindo-se à exploração extensiva do trabalho, Marx falava do "paradoxo econômico que torna o mais poderoso meio de encurtar o tempo de trabalho no meio mais infalível de transformar todo o tempo da vida do trabalhador e de sua família em tempo de trabalho de que pode lançar mão o capital para expandir seu valor"16. A crítica posterior, com ênfase para aquela vinculada à Escola de Frankfurt, com Adorno e Horkheimer, estaria atenta ao fato de que todo o tempo (inclusive aquele dedicado ao lazer, na crítica dos autores à cultura de massas) ficaria submetido à lógica alienante do capitalismo. Inspirada nas análises de Michel Foucault, Michelle Perrot caminha em sentido semelhante. Após a exposição e discussão de uma série de mecanismos utilizados para o disciplinamento dos trabalhadores durante o século XIX, na França, a autora observa o avanço da industrialização segundo a seguinte problemática:

Cada vez mais invisível e distante, a disciplina também é cada vez mais interiorizada. Pela educação (em sentido muito amplo), os valores da utilidade e do trabalho modelaram a consciência dos homens que se definem por seu lugar num processo de trabalho. A consternação dos desempregados (operários ou principalmente funcionários) diante do desemprego, e não só por razões materiais, mostra como por vezes é difícil viver um "tempo livre". Os operários do início do século XIX ficavam desconcertados com o trabalho; nós ficamos desconcertados com a liberdade! Nosso contramestre é nossa consciência ${ }^{17}$.

No que se refere ao jornalismo, em seu desenvolvimento mais atual, que decorre, segundo defendo, da reprodução e do aprofundamento do modelo que se definia a partir de meados do século XX, a adoção de novas tecnologias permitiu a extensão maior do dia de trabalho, e não o seu encolhimento. Como o jornal pode ser impresso e distribuído com mais rapidez, o "fechamento" das edições se estendeu, sendo realizado, em alguns casos, às 22 ou 23 horas - ou mesmo no início da madrugada do dia seguinte -, pela possibilidade técnica de incluir no jornal do dia posterior os fatos ocorridos no final do dia ou à noite, aproximando-se, portanto, do conteúdo que é potencialmente disponível aos telejornais noturnos. O horário e o desgaste do trabalho nas redações se viram, assim, ampliados pelo "progresso técnico" e naturalizados pelos dispositivos de disciplinamento e seleção dos jornalistas, que passam pela valorização e reconhecimento dos mais hábeis a enfrentar as exigências dessa rotina, reproduzindo-a e reconhecendo sua legitimidade. 
Na documentação trabalhada, a imagem da fábrica trepidante, de que lançamos mão para discutir os sentidos que organizam a relação entre disciplina, tempo de trabalho e tempo de vida, se associa à valorização do "jornalista 24 horas", que será discutida a seguir. Nesses discursos, o próprio esgotamento acaba sendo tratado como marca valorativa, como atrativo. Mesmo quando o ritmo de trabalho e os plantões ganham descrições mais negativas, essas descrições estabelecem marcas valorativas de diferenciação em relação a outras profissões. Como se disse antes, a produção de uma identidade para o grupo e o disciplinamento são inseparáveis na configuração do “jornalista moderno".

A valorização da produtividade do trabalhador parece ser de tal modo estruturante do "jornalismo moderno", no Brasil contemporâneo, que a extenuação pode, ela mesma, ser descrita em tom eufórico ou romântico, sendo ela mesma um dos elementos que organizam a relação entre disciplina e produtividade nos discursos abordados no próximo item.

\section{O jornalista 24 horas}

No final dos anos 1940 e início dos 50, começou a tomar corpo, entre os jornais brasileiros, a prática de editar manuais ou conjuntos de regras, visando a normatização do trabalho jornalístico. Foram editados, nessa época, os primeiros manuais ou normas para a redação e publicação de textos nos grandes jornais, contendo regras que ultrapassavam aspectos formais, procurando organizar e disciplinar o trabalho nas redações. Não quero dizer que esse trabalho se realizasse, antes, sem normas ou hierarquias. Mas foi naquele momento, coincidente com a ampliação das empresas, com uma divisão maior das funções e com o surgimento das primeiras escolas de jornalismo, que houve uma maior explicitação dessas normas, inspiradas no estilo norte-americano de jornalismo, que se firmou como modelo para o brasileiro pelo menos desde os anos 1920.

Neste artigo, não há uma discussão específica sobre o modelo norte-americano de jornalismo e sua relação com as transformações no jornalismo brasileiro. É importante ressaltar, no entanto, como o faz Albuquerque, que não se deve pensar em “adoção", mas em uma "adaptação" do modelo norte-americano de jornalismo ${ }^{18}$. Devese, assim, analisar como as especificidades do jornalismo no Brasil (e de sua inserção política e empresarial) constituíram um conjunto de valores e práticas que promovem 
uma identidade para os jornalistas ao mesmo tempo em que promovem formas de controle da perspectiva das empresas, constituindo também as relações com o público.

Foi na segunda metade do século XX que a divisão do trabalho e sua normatização passaram a ser mais acentuadas nas redações dos jornais no Brasil. Como nos escritos e padrões normativos dos anos 1950, ou naqueles que definem as transformações então ocorridas, continuariam a aparecer juntos e de maneira pouco problematizada o progresso técnico e os dispositivos de disciplinamento, muitas vezes legitimados e naturalizados por supostas necessidades que aquele progresso imporia. Nesse sentido, as normas de conduta são muitas vezes apresentadas como necessidades técnicas - e a técnica, muitas vezes, é apresentada como dado natural e não como um conjunto de formas de organização e racionalização do trabalho em busca de efeitos determinados.

Isso não se dá, obviamente, apenas no campo jornalístico. Parece ter peculiaridades no campo jornalístico, no entanto, a valorização simultânea do trabalhador normatizado e disciplinado, definido como peça em uma maquinaria industrial complexa, e a valorização do jornalismo como vocação e como missão. Os efeitos são interessantes: ao mesmo tempo em que o disciplinamento, a rapidez maquinal e a objetividade deveriam estruturar o comportamento do trabalhador (o que implica o império da norma sobre a subjetividade), ele deveria sentir-se imbuído de uma nobre missão para a qual servirá tão melhor quanto maior for sua vocação (o que implica a valorização da subjetividade e da competência jornalística como uma espécie de característica nata). Mais uma vez, controle e identidade do grupo constituem uma mesma dinâmica.

Natalício Norberto, em livro escrito no início dos anos 1950 com o intuito de orientar aqueles que desejassem dedicar-se à profissão, procurando passar a eles o que, ao chegar às redações, teria aprendido a duras penas no trabalho cotidiano (é o que diz a apresentação do livro), afirma que o jornalismo, no Brasil daqueles dias, já era "uma profissão", com a ressalva de que envolvia também negócio, dinheiro, prestígio, o que fazia com que muitos quisessem ser jornalistas pelo salário, para "ter cartaz", para não pagar imposto de renda. $\mathrm{Na}$ seqüência, porém, afirmava: "Na realidade, jornalismo é luta, sonho, corre-corre, vibração, obstáculo, dificuldade. E muito mais: é vocação. Talento aliado à prática e a uma boa dose de cultura geral. Tarimba acima de tudo. ... para ser jornalista é preciso ter queda"19. 
O conjunto de normas editado pela Tribuna da Imprensa, jornal que pertenceu a Carlos Lacerda e que foi bastante ativo na oposição a Getúlio Vargas durante os anos 1950 e na defesa da orientação política de seu proprietário (aí incluída a defesa de intervenções golpistas, culminando na participação de Lacerda na articulação do golpe de 1964), traz, entre orientações de caráter técnico, as seguintes:

\footnotetext{
"Pense que não exerce apenas uma função, mas uma missão. Sua função é informar-se. Sua missão, informar";

"Seja jornalista todo o tempo - ou nunca será jornalista";

"Quem vê no jornal apenas um emprego deve empregar-se na Prefeitura";

"Quando tiver de prejudicar alguém no interesse público, pense duas vezes. Quando tiver de favorecer alguém, em particular, pense duas vezes. Quando tiver de prejudicar o interesse público, nem precisa pensar: rasgue o que escreveu";

"O seu melhor crítico é o editor imediatamente responsável pelo seu trabalho";

"Não faça gastar tempo e dinheiro com originais mal escritos, mal revistos, desordenados". ${ }^{20}$
}

Chama a atenção, ainda, o fato de que, entremeada a regras de redação que recomendam o uso do lead, nomeado "guia",21, assim como a pirâmide invertida (as informações principais, "objetivas" digamos, precedendo o desenvolvimento da notícia), esteja presente uma observação como esta: "O horário legal é de 5 horas. Mas só se é jornalista 24 horas por dia”.

Nos manuais de redação dos anos 1940-60, vírgulas, pontos, maiúsculas e a exigência do lead confundiram-se com o direcionamento do que deveria ser visto e reportado pelo jornalista, não durante o período de trabalho, mas durante todos os momentos de seu dia: profissão-missão, intenção totalizadora a favor da imagem das empresas, do rendimento, da constituição da credibilidade como um dos focos de poder e de lucro dessa atividade. Essa vinculação entre objetivos empresariais e a missão ou competência individual do jornalista, no entanto, nem sempre foi explicitada nos compêndios de normas editados pelos grandes jornais da época. Mesmo a concepção hierárquica do processo de produção da notícia esteve, muitas vezes, apenas implícita nesses textos. As normas da Tribuna da Imprensa, por exemplo, apresentaram apenas observações como esta: "Quando tiver dúvidas sobre a responsabilidade que uma matéria acarreta ao jornal, consulte o responsável pela sua seção: lembre-se que o jornal pode pagar pela sua distração ou leviandade",22.

Nabantino Ramos, que dirigiu os jornais Folha da Manhã, Folha da Tarde e Folha da Noite, pertencentes à empresa Folha da Manhã, entre 1945 e 1962, quando passariam à direção da família Frias, expressa as razões para a introdução de normas para o trabalho jornalístico naqueles jornais da seguinte forma: 
Um tal poder, assim extenso e grave [o da imprensa], não deveria funcionar à mercê da negligência ou do zelo, da cupidez ou do desprendimento, do ódio ou da amizade de nenhum jornalista;

Procedendo eu da advocacia, que se desenvolve sob a disciplina de normas, sentia, como diretor de jornal, a falta de regras, tanto para o trabalho diário, como para reger as relações do periódico com o meio em que atuava. ${ }^{23}$

No verbete "Normas de Trabalho" do Dicionário Enciclopédico de Jornalismo, publicado em 1970, Ramos explicaria mais uma vez a ampliação da rigidez normativa e da padronização nas redações dos jornais que comandava:

O pequeno jornal, que é feito por poucas pessoas, situadas em uma ou poucas salas, não precisa de Normas de Trabalho. O dono é a lei e sua presença basta para orientar o serviço da Redação, quando ele queira que seja feito dentro de certo padrão.

Mas isso não acontece com o grande jornal, feito por muita gente. Ou se faz trabalho contraditório, incoerente e até mesmo anárquico, para o que não se precisa de Normas, ou se quer trabalho coerente, coordenado, dentro de determinada orientação, e para isso elas se tornam imprescindíveis. As Normas são para um jornal o que o Código de Processo é para a Justiça. ...

A imprensa adulta também opera dentro de Normas, em todas as etapas de seu trabalho. As atribuições de cada chefe estão escritas. A maneira de escrever, de usar certas palavras, está disciplinada. O que se deve e o que não se deve publicar, também está previsto. ${ }^{24}$

Décadas depois, o Novo Manual de Redação da Folha de S.Paulo, de 1992, apresentaria entre seus itens algo que não estava presente nas disposições normativas produzidas nos tempos de Nabantino Ramos, e que reforçaria o discurso do jornalista 24 horas em um padrão jornalístico que resulta, fortemente, das expectativas de normatização, disciplinamento e homogeneização enunciadas por Ramos:

Disponibilidade: O jornalista da Folha está sempre investido de sua condição. Mesmo em folga ou em férias, quando for imperioso, deve obedecer à convocação do jornal. Ainda que não esteja em horário de trabalho, deve produzir reportagem quando testemunhar fato de grande interesse jornalístico. $^{25}$

O item seguinte, "Engajamento", relaciona, então, o jornalista 24 horas - que compõe o ideário da totalização da experiência e dos sentidos pelo ritmo e pelas exigências da produção jornalística e pelas regras e imposições das empresas de comunicação - ao jornalista isento - que compõe o ideário da isenção como forma de controle das percepções e enquadramentos do trabalhador, aspecto que será discutido mais adiante neste artigo. Pode-se ler:

Engajamento - A Folha considera que o engajamento em organizações político-ideológicas pode prejudicar o desempenho profissional do jornalista, em especial daquele que cobre a área política. Não se espera, com isso, que o jornalista não tenha ideologia, opiniões e preferências, mas que tenha sempre em mente que o envolvimento partidário o torna vulnerável a paixões, parcialidade, falta de espírito crítico e mesmo ingenuidade. ${ }^{26}$ 
Pode-se inferir, daí, que o profissional será mais valorizado quanto mais disponibilidade tenha para o trabalho jornalístico - em termos cognitivos, já que essa disponibilidade inclui ver a realidade com olhos de jornalista, e em termos de disposição objetiva de seu tempo, já que deve ser jornalista mesmo fora de seu horário de trabalho - e quanto menos envolvimento tenha com a realidade extrajornalística, que incluiria posicionamentos, parcialidade, envolvimento, crenças.

Algumas formulações nesse sentido, mais próximas cronologicamente dos tempos em que Nabantino coordenou as Folhas, chegariam à observação, ainda que despida de crítica, de que as rotinas de trabalho assim orientadas incidiriam sobre o corpo dos trabalhadores. Uma publicação do governo norte-americano do ano de 1948 explicava o que era preciso para um indivíduo tornar-se jornalista:

\footnotetext{
Para tornar-se um repórter ou editor, você deve, em primeiro lugar, ser capaz de escrever textos interessantes, de maneira rápida e acurada, com respeito à redação, à gramática, e aos fatos. Você deve ter interesse por um amplo espectro de informações gerais, e deve ser capaz de conversar sobre vários tópicos com todos os tipos de pessoas, como políticos, empresários, líderes dos trabalhadores, para conseguir material para sua estória. Você deve ter uma mente questionadora que não aceita nada como dado e busca causas e fatos reais. Você precisará de um "faro para notícias", isto é, uma habilidade para determinar o que compõe uma estória que interessará aos leitores. Você deve ter capacidade para observação acurada das pessoas e de seu comportamento, e ser capaz de escrever descrições claras, breves e exatas de eventos, coisas e pessoas. Boa saúde e resistência são importantes devido a horas irregulares de trabalho e à necessidade de trabalhar sob pressão para atender aos horários de fechamento. ${ }^{27}$
}

Como essa publicação que acabo de citar, outras publicações norte-americanas, traduzidas para o português no período, contribuiriam para a cristalização dessas imagens: trabalho sob pressão, dedicação, normatização e missão compõem os discursos. Os principais exemplos, nesse sentido, são o Manual de Jornalismo de John Hohenberg, que teve sua primeira edição brasileira em 1962, e o "guia” de Fraser Bond, publicado no Brasil em 1959. Nessas publicações, encontram-se, também como valores centrais, a objetividade e a isenção, aqui consideradas como dispositivos importantes para o disciplinamento do olhar e da escrita dos jornalistas, pontos que serão discutidos a seguir ${ }^{28}$.

\section{O "jornalismo crítico" desprovido de autores}


A valorização da técnica, unida ao ideário da isenção, foi um dos componentes principais das projeções sobre o "jornalismo moderno" nos compêndios normativos e em textos escritos por jornalistas durante as décadas de 1940-60.

No que se refere ao controle da escrita pela valorização da forma e da norma, Natalício Norberto, citado antes nesse artigo, fazia coincidirem "faro da notícia", regras de apuração e a indicação de que a escrita breve, precisa e honesta é que faria, mais do que tudo, o repórter, o bom jornalista. Suas palavras, datadas do início da década de 1950, demonstravam uma percepção da relação entre norma (neste caso, a norma gramatical) e credibilidade, em relação à qual podemos construir um paralelo com a vinculação entre a disciplina, que tem como aspecto importante a padronização e ordenação da escrita, e a eficiência empresarial, ambas centrais em busca de maior lucratividade ${ }^{29}$.

Mas são os referenciais da objetividade e da isenção que permeiam mais amplamente os discursos, em um duplo movimento: o do disciplinamento da escrita e o da legitimação da informação jornalística como verídica e necessária.

O "Programa de Ação das Folhas", produzido em 1948, quando Nabantino Ramos dirigia a empresa Folha da Manhã, foi pioneiro nos esforços de padronização e disciplinamento de jornais e jornalistas no Brasil. Explicitava pouca preocupação com questões formais, que estariam presentes em maior quantidade e com maior determinação em normas produzidas em $1959^{30}$. Não deixaria, porém, de tocar em um dos temas que seriam recorrentes nos manuais que surgiram a partir dos anos 1950, nas discussões de jornalistas ativos na época ou em suas memórias: o tema da delimitação entre informação e opinião.

No "Programa", o item Informação enfatiza, como um dos propósitos explicitados pelos jornais da empresa Folha, a "fidelidade aos acontecimentos" "Sejam bons ou maus, agradem ou não a quem quer que seja, os fatos aparecerão sempre nas Folhas, com o relevo adequado, conforme se trate do matutino ou do vespertino" ${ }^{\prime 31}$.

O item Opinião, por sua vez, discorre sobre os problemas a que os três jornais deveriam dedicar-se, os quais deveriam ser abordados "sem paixão", preferindo opiniões "mais seguras do que brilhantes". Esse ponto se articula com a novidade implementada por Nabantino Ramos na época: as comissões de "especialistas" que debateriam os temas, indicando a orientação dos editoriais e artigos e que, segundo a 
perspectiva institucional contida no texto, deveriam ter como preocupação principal a conveniência dos fatos noticiados e de seus desdobramentos para o "interesse público".

A delimitação entre informação e opinião estaria presente também em manuais recentes. No "Manual de redação e estilo" do jornal O Estado de S. Paulo, de 1990, a apresentação do jornalista Augusto Nunes cuida de ressaltar uma suposta diferença entre esse e outros manuais, "aparentemente forjados para a fabricação em série de jornalistas de proveta, robôs infensos a qualquer gênero de emoção". De modo semelhante, o também jornalista Eduardo Martins, organizador do manual, afirma no prefácio que as normas não pretendem "tolher a criatividade de editores, repórteres e redatores, nem impor camisas-de-força aos jornalistas da empresa". Seu objetivo seria o de "definir princípios que tornem uniforme a edição do jornal”. As Instruções Gerais do manual recomendariam, no entanto, de modo semelhante aos demais: "Faça textos imparciais e objetivos. Não exponha opiniões, mas fatos"; "Lembre-se de que o jornal expõe diariamente suas opiniões nos editoriais, dispensando comentários no material noticioso". Depois, entre as Instruções Específicas, o item "Opiniões” reafirmaria as normas, lembrando que "o jornal, como um todo, tem opiniões sobre os assuntos que publica e as expressa em editoriais". Por isso, o noticiário deveria ser "essencialmente informativo, evitando o repórter ou redator interpretar os fatos segundo sua ótica pessoal", o que incluiria "a distorção ou condução do noticiário".

Se no Manual de 1990 do Estado, assim como em outros manuais, atuais e das décadas finais do século XX, os elementos mais ressaltados, sempre unidos, parecem ser a correção no uso da língua (a norma lingüística) e a objetividade como transcrição correta dos fatos, com o mínimo possível de intervenção do jornalista, nos textos das décadas anteriores, esse cruzamento já se expunha, mas um outro ocupava posição também central: vocação e objetividade eram igualmente valorizadas como características do "jornalista moderno", em um dos matizes da sobreposição entre vocação e técnica, mencionada antes.

Luiz Beltrão define o jornalista adequado como aquele que "encontrou a sua vocação no servir de porta-voz e intérprete dos fatos sociais". Essa "voz interior", esses "dons inatos e magníficos da alma e da personalidade" deveriam ser aprimorados pela formação cultural e pelos conhecimentos técnicos, pela prática do jornalismo, através da qual seriam consolidados e desenvolvidos. Mas determinariam, de antemão, uma característica essencial e indispensável ao jornalista: a aspiração de $\operatorname{servir}^{32}$. Quando o assunto é "objetividade", aparece novamente uma definição de características essenciais 
que comporiam o jornalista: "outro traço marcante de sua personalidade é a objetividade, o apego à verdade, ao realismo, ao sucedido" ${ }^{\text {33 }}$. Entre citações de Tristão de Ataíde, de Antonio Olinto e do Papa Pio XII, Beltrão afirma o ideal da objetividade e da isenção, indicando os obstáculos que a ele se imporiam (todos eles considerados "ruídos" a serem superados). Destaco a seguinte formulação de Tristão de Ataíde, reproduzida por Beltrão:

\begin{abstract}
Tudo deriva daí: a informação do fato; a formação pelo fato; a atualidade do fato; o estilo determinado pelo fato. $\mathrm{O}$ fato, o acontecimento, é a medida do jornalista ... A veracidade, o realismo, é a sua grande força. $\mathrm{O}$ mau jornalista é o sofisticado ou o fanático, ou o mal informado, ou o divagante ou o vernaculista. Todos eles perdem de vista o objeto, o fato, a realidade para se prenderem apenas no modo de o retratarem ou nas suas segundas intenções mais ou menos ocultas. ${ }^{34}$
\end{abstract}

O jornalista - ou o mau jornalista - seria, assim, prevenido quanto à sofisticação da linguagem e o uso de adjetivos, não permitidos em normas das décadas de 1940 e 50 - "Não serão permitidos adjetivos no noticiário, bem como insinuações ou comentários do autor de cada notícia", diziam as normas da Agência Meridional de Notícias, pertencente aos Diários Associados ${ }^{35}$ - ou em manuais mais recentes, como o "Novo Manual da Redação" da Folha de S.Paulo, que previne os repórteres quanto ao uso de adjetivos em textos noticiosos (principalmente os que implicam juízos de valor, considerados "duvidosos") e explica que há maior liberdade para seu uso em editoriais, comentários, críticas e artigos: "mesmo assim, recomenda-se usá-lo com sobriedade. A opinião sustentada em fatos é mais forte do que a apenas adjetivada"36.

A contraposição entre o jornalismo europeu (ou o modelo francês, como é em geral definido) e o norte-americano foi bastante utilizada, nas fontes pesquisadas das décadas de 1940-60, para reforçar o vínculo entre jornalismo objetivo e moderno, que deixaria para trás o jornalismo de opiniões e de indisciplinados.

Se, como indicam estudos como os de Schudson e Tuchman, a "objetividade" no jornalismo norte-americano se desenvolve como valor específico, ligado a aspectos históricos do desenvolvimento profissional e das relações entre jornalismo e política e à promoção de uma identidade para os jornalistas (Schudson), ligado também a rotinas produtivas nas quais aparece como um "ritual estratégico" para a defesa dos jornalistas diante das exigências dessas rotinas, dos superiores hierárquicos e mesmo de processos que possam ser movidos contra eles (Tuchman), o que vemos nas formulações analisadas neste artigo é uma condensação de visões idealizadas da "objetividade" no 
jornalismo, conectadas a noções de progresso e modernidade. Essas idealizações funcionam, nos discursos, para justificar as formas assumidas pela rotina jornalística e pelo próprio profissional do jornalismo: elas aparecem como formas necessárias porque vinculadas a uma evolução e progresso das competências profissionais desse campo, diante das exigências que a "atualidade" lhes imporia ${ }^{37}$.

Em um artigo publicado em 1961, o jornalista Victor da Cunha Rêgo fez diversas considerações a esse respeito. Uma Europa decadente, "velha, cansada", com uma imprensa envelhecida e cínica, aparece, no texto de Cunha Rêgo, contraposta aos Estados Unidos e à "primeira linha" do jornalismo mundial. O contraponto inclui afirmações de que na Europa (a França é o exemplo principal) o jornalismo se fazia então sem regras, "muito mais subordinado à forma literária, ao barroco da composição gramatical, do que à exposição dos fatos reais": as inovações técnicas eram, segundo o jornalista, combatidas, as notícias eram fortemente editoriais e os editoriais poderiam ser considerados notícias, em um modelo de jornalismo no qual "a auto-suficiência é o lema do dia-a-dia profissional". A este último ponto é que Cunha Rêgo direcionava, em especial, sua crítica.

O jornalismo norte-americano, por sua vez, consistiria na predominância de fatos, e não impressões. "Não há demagogia que lhe estrague o estilo - dizia -, não há redatores que façam a guerra 'por su cuenta', não há presunção"; fazia-se, ali, na opinião de Cunha Rêgo, o melhor dos noticiários. A principal razão dessa mudança, vista como evolução, seria "a existência de uma série de regras na feitura dos periódicos". As fragilidades do modelo, segundo ele, estariam no excesso de preocupação com os pequenos fatos, com uma eficiência padronizada que restringiria os jornalistas à "função mecânica de colher e transmitir dados sem análise". "Os jovens repórteres acreditam piamente no seu trabalho e no entanto a burocracia, ou melhor, a mecanização, toma-lhes conta da vida", dizia. Essa percepção e a crítica que encerra não impediriam que o jornalista manifestasse sua preferência pela "solução americana", justificada pela crença "mais nas investigações de rotina com bons fichários, bons laboratórios e sentido de responsabilidade do que na auto-suficiência"38.

Foi comum, neste tipo de posicionamento, uma confusão explícita entre um modelo (o norte-americano), os ideais a ele ligados e as noções de modernidade e progresso $^{39}$. Vale a pena acompanhar o seguinte texto, de autoria de Austregésilo de Ataíde: 
Eis a chave do jornalismo da nossa atualidade, o elemento revolucionário que lançou uma linha divisória entre a velha imprensa e a imprensa moderna e que coloca quase como antípodas o editorialista que, pela sua energia, tenacidade e bravura pessoal, pelas qualidades do seu raciocínio, firmeza e teimosia em expô-lo, era, sozinho, o jornal ..., e o próprio jornal de agora, que supera o jornalista, é maior que ele, sobrevive à sua ação ...

Foi preciso transcorrer muito tempo, mais de três séculos, antes que a imprensa encontrasse elementos substanciais e próprios de sua expressão, antes que o jornalismo se emancipasse de conexões desfiguradoras, da tirania obsessiva do jornalista com as suas qualidades pessoais, para ser uma entidade autônoma, apoiado principalmente na soberania e indiscutibilidade do fato. ${ }^{40}$

Décadas depois, o "Projeto Folha" definiria o jornalismo moderno de maneira diferente da de Ataíde. Consistiria, segundo consta no "Novo Manual de Redação" do jornal, em princípio editorial que defende a introdução de novos temas na discussão pública, novos enfoques, preocupações e tendências. Pouco mais de uma página depois, no entanto, ao ensaiar uma posição diferenciada sobre a objetividade, o manual repetiria formulação que não se distancia da de Ataíde no texto de 1958: não existe objetividade, afirma, "ao escolher um assunto, redigir um texto e editá-lo, o jornalista toma decisões em larga medida subjetivas, influenciadas por suas posições pessoais, hábitos e emoções”, mas a obrigação do jornalista é a de ser "o mais objetivo possível”, "encarar o fato com distanciamento e frieza" ${ }^{, 4}$. As qualidades pessoais ou a própria presença do jornalista, de suas percepções e de seu olhar, aparecem no "Projeto" como um empecilho à "soberania e indiscutibilidade do fato". As continuidades parecem sobrepor-se fortemente à intenção de novidade anunciada.

Até este ponto do texto, a objetividade apareceu aliada a estratégias de diminuição da presença e da autonomia do jornalista, em nome do rendimento, da padronização e da uniformização. Mas há perspectivas diferenciadas. Ao mesmo tempo em que faz parte dos esforços disciplinadores, que caminhariam no sentido da diminuição da autonomia daquele que escreve, o valor objetividade pode ser mobilizado para a proteção do próprio jornalista diante de práticas de manipulação, falseamento e/ou silenciamento por parte da direção das empresas.

Parecem ser ao menos duas as possibilidades para o trabalho no campo do ideário da isenção e imparcialidade, nos textos analisados neste artigo: de um lado, uma garantia maior de controle das empresas sobre aquilo que se produz, pela delimitação da autonomia do jornalista como autor, com o disciplinamento de seu olhar e de sua escrita; de outro, a possibilidade de uma defesa da ética no jornalismo por parte dos trabalhadores da notícia. O problema parece estar no fato de que essa defesa da ética recorra ao mesmo campo, falacioso, da possibilidade de reprodução dos fatos tais quais 
são e de produção de uma verdade que paira acima das perspectivas e conflitos presentes nas sociedades.

O primeiro item da "Declaração de Londrina", resultante do I Encontro de Jornalistas do Paraná, realizado em Londrina entre 29 de junho e $1^{\circ}$ de julho de 1962 , defendia a "criação de uma consciência profissional de que o jornalista é, cada vez mais, um trabalhador assalariado e cada vez menos responsável quer pela opinião difundida pela empresa em que trabalha, quer pela deformação interessada da notícia” ${ }^{, 42}$, em uma demonstração de que a concepção da autoria no jornalismo se transformava. Nesse caso, a caracterização do jornalista como "trabalhador assalariado", inserido em uma situação em que se sente estranho em relação ao produto final de seu trabalho (o jornal do dia seguinte), é mobilizada em defesa do próprio jornalista, que não poderia, assim, ser responsabilizado legalmente pelos textos veiculados nos jornais.

Resoluções de outro encontro da mesma época, o X Congresso Nacional de Jornalistas, que aconteceu em Brasília entre os dias 3 e 7 de julho de 1963, afirmavam, por sua vez, que

a) o jornalista deve desfrutar, como trabalhador intelectual, de liberdade intelectual e de convicção, liberdade essa que deve se traduzir na prática, pelo direito de não escrever contra sua própria consciência e contra o que julga serem os interesses da comunidade, a serviço da qual deve estar;

b) o jornalista deve sempre dar a informação verídica, sem deformações interessadas, sem subordinação a grupos contrários ao conhecimento dos fatos, que devem ser apresentados tal como ocorreram. ${ }^{43}$

Nesse último caso, a defesa da "liberdade intelectual" é associada, não à manifestação de posições e percepções diversas, mas à possibilidade de "dar a informação verídica", transmitir fatos sem deformações, dissolvendo as potencialidades de uma concepção mais autônoma de autoria em nome da construção de um lugar neutro e desinteressado.

De modo semelhante, nos textos que tratam da formação do "novo jornalista", muitos deles vinculados aos primeiros cursos de jornalismo nas faculdades e universidades brasileiras (aspecto que não foi possível discutir neste artigo), a questão da autoria mais autônoma ou da pluralidade de opiniões e visões é silenciada em nome da técnica e da especialização: "aquela figura boêmia dos tempos românticos do jornalismo ficou para o passado", afirmava o então diretor do curso de jornalismo da PUC-RJ, Walter Ramos Poyares, em sua apresentação ao manual de Fraser Bond ${ }^{44}$. Menos boemia e mais rendimento, menos marcas subjetivas no trabalho e maior 
adaptação à rotina das redações compunham os argumentos sobre o jornalismo moderno. Os cursos não formariam "doutores em jornalismo", dizia, em uma resposta a debates da época sobre o caráter dos cursos, mais voltados para as humanidades ou mais técnicos. Com eles, explica, "simplesmente estamos vencendo o tempo, reduzindo o período de adaptação, praticamente ultrapassando a era do 'foca'. O bom curso apresentará o diplomado já apto a trabalhar com bom rendimento".

Essas formulações projetam o profissional moderno, formado e adaptado para a disciplina das redações, na medida em que afirmam um conjunto de valores que deveriam, necessariamente, referenciar suas práticas. A valorização da técnica, mais ou menos associada à idéia de "vocação", constitui o elemento central desses discursos. Neles, como se disse ao longo deste artigo, identidade e controle, valores compartilhados e disciplinamento, são constitutivos da dinâmica de transformações que define, nas fontes trabalhadas, a face do "jornalista moderno".

Unidos a outros fatores - como o grande número de jovens jornalistas semestral ou anualmente colocados no mercado pelas faculdades de jornalismo, o receio do desemprego, assim como os efeitos de mais de 20 anos de arbítrio e censura que marcaram o jornalismo feito no país -, os dispositivos de controle do tempo, do olhar e da escrita dos profissionais parecem ter contribuído, de fato, para a construção do “jornalismo moderno": a máquina funcionaria, cada vez mais, sem a necessidade de um controle externo, proveniente das hierarquias existentes nas redações ou da direção das empresas. A disciplina surtiria efeito na medida justamente em que se materializa em um conjunto de referenciais identitários, definindo valores compartilhados e o status profissional daqueles que, ao mesmo tempo, estão a ela submetidos e são os principais agentes na promoção de sua aceitação e reprodução.

\section{REFERÊNCIAS BIBLIOGRÁFICAS:}

ABREU, A. A. de et alli. A imprensa em transição: o jornalismo brasileiro nos anos 50. Rio de Janeiro: Ed. FGV, 1996.

ALBUQUERQUE, A. de. Another "fourth branch": press and political culture in Brazil. Journalism, v. 6 (4), 2005. p. 486-504.

AQUINO, M. A. de. Censura, imprensa, Estado autoritário (1968-78). Bauru, SP: Edusc, 2002. 
ATAÍDE, A. de. O Jornalismo Atual. In: Curso de Jornalismo - Conferências Realizadas na Associação Brasileira de Letras. Rio de Janeiro: ABL, 1958.

ATAÍDE, T. O jornalismo como gênero literário. Diário de Notícias, Rio de Janeiro, $10 / 11 / 1957$.

BAHIA J. Jornal, história e técnica: história da imprensa brasileira. 4. ed. São Paulo: Ática, 1990.

BELTRÃO, L. Iniciação à filosofia do jornalismo. Rio de Janeiro: Livraria Agir Ed., 1960.

BOND, F. Introdução ao jornalismo. Rio de Janeiro: Livraria Agir Ed., 1959.

CAPELATO M. H. e MOTA, C. G. História da Folha de S.Paulo (1921-1981). São Paulo: Impres, 1980.

DINES, A. O papel do jornal: uma releitura. 4. ed. São Paulo: Summus, 1986.

FOUCAULT, M. Vigiar e punir. Petrópolis: Vozes, 1987.

A vida dos homens infames. In: $O$ que é um autor. 3. ed. Portugal: Veja, 1992.

. Conferência V. A verdade e as formas jurídicas. Rio de Janeiro: Nau; PUC, 1999.

HOHENBERG, J. Manual de jornalismo. Rio de Janeiro: Ed. Fundo de Cultura, 1962.

JOBIM, D. Jornalismo e técnica. Espírito do jornalismo. São Paulo: Com arte/Edusp, 1992, v. 6. Col. Clássicos do jornalismo brasileiro.

KUSHNIR, B. Cães de guarda: jornalistas e censores. São Paulo: Boitempo, 2004.

LIMA, R. Jornalismo e democracia. Ministério da educação e cultura, Serviço de documentação, s/d.

MARX, K. O capital. Livro 1, Parte IV, Cap. 12, item 3.

MEDINA, C. Notícia: um produto à venda - Jornalismo na sociedade urbana e industrial. São Paulo: Alfa-Omega, 1978.

NORBERTO, N. Jornalismo moderno. Rio de Janeiro: Gráfica Editora Itambé Ltda., $\mathrm{s} / \mathrm{d}$.

PERROT, M. As três eras da disciplina industrial na França do século XIX. In: Os excluídos da história: operários, mulheres, prisioneiros. 2. ed. Rio de Janeiro: Paz e Terra, 1992.

RAMOS, N. Jornalismo: dicionário enciclopédico. São Paulo: Ibrasa, 1970.

REGO, V. C. Jornais e Jornalistas. Órgão Oficial da APISP (Associação dos Profissionais de Imprensa de São Paulo), 1961. 
RIBEIRO, A. P. Goulart. Imprensa e história no Rio de Janeiro dos anos 50. Rio de Janeiro: E-papers, 2006.

SCHUDSON, M. The objectivity norm in American journalism. Journalism, v. 2 (2), 2001. p. 149-170.

SILVA, C. E. Lins da. $O$ adiantado da hora: a influência americana sobre o jornalismo brasileiro. São Paulo: Summus, 1991.

SODRÉ, N. W. História da imprensa no Brasil. 2. ed. Rio de Janeiro: Graal, 1977.

SUARÉE, Octávio de la. Psicologia aplicada al periodismo. La Habana, 1944.

TUCHMAN, G. Objectivity as strategic ritual: an examination on newsmen's notion of objectivity. American Journal of sociology. v. 77 (4). Chicago, 1992, p. 660-79.

BIROLI, Flávia. Power techniques, disciplines for observation: some aspects of the making of "modern journalism" in Brazil. História, São Paulo, v. 26, n. 2, p. 118- 143, 2007.

Abstract: This article focuses on the relations between the changes in journalism during the XXth century and the build-up of journalists as productive and disciplined workers. It analyses a series of discourses, produced in Brazil after the 1940s, that converges in mechanisms for the discipline of observation and writing, in techniques for the disposing of time, experiences and bodies, affecting journalists and their readers.

Key-words: journalism, discipline, norm.

Artigo recebido em 10/2007. Aprovado em 12/2007.

\section{NOTAS:}

\footnotetext{
* Professora adjunta do Instituto de Ciência Política da Universidade de Brasília (Ipol-UnB), Brasília, Distrito Federal, Brasil. E-mail: fbiroli@terra.com.br

${ }^{1}$ Para análises mais focadas no contexto das transformações ocorridas na imprensa a partir dos anos 50 e 60, no Brasil, conferir A. A. de Abreu et alli (1996); N. W. Sodré (1977); J. Bahia (1990) e A. P. Goulart Ribeiro (2006). Para análises focadas nas questões relativas à conformação do modelo norte-americano de jornalismo, que tem a noção de objetividade como dispositivo central, e à adoção desse modelo pela imprensa brasileira, cf. M. Schudson (2001, p. 149-170); A. de Albuquerque (2005, p. 486-504) e C. E. Lins da Silva (1991).

${ }^{2}$ Schudson, op. cit., p. 152-3.

${ }^{3}$ Foucault, 1987, p. 119.

${ }^{4}$ Muitas das petições analisadas pelo autor foram enviadas ao rei por súditos que desejavam a punição de pessoas próximas, supostamente "perversas". Já as lettres de cachet eram documentos emitidos em nome do rei determinando a prisão, internamento ou algum outro tipo de sanção a pessoas consideradas "nocivas" à sociedade (Foucault, 1992, p. 89-126).

${ }^{5}$ Foucault, 1987, p. 119.

${ }^{6}$ Foucault, 1992, p. 122-3.

${ }^{7}$ Foucault, 1999, p. 103-126.

${ }^{8}$ A esse respeito, cf. M. A. de Aquino (2002) e B. Kushnir (2004).
} 
${ }^{9}$ A esse respeito, cf. Ribeiro (op. cit.).

${ }^{10}$ Jobim, 1992, p. 72. Jobim foi diretor do Diário Carioca, referência para as reformas gráficas e de texto na imprensa carioca dos anos 1950. Os textos presentes na coletânea aqui utilizada resultaram de cursos ministrados por ele em 1953 e 1957, na Universidade do Texas (Austin, EUA) e na Sorbonne (Paris, França).

${ }^{11}$ Normas do jornal O Estado de S. Paulo, in J. M. de Melo (org.), Normas de redação de cinco jornais brasileiros. São Paulo: Escola de Comunicações e Artes, Universidade de São Paulo, 1972, p. 83.

12 BAHIA, op. cit., p. 203.

${ }^{13}$ Medina, 1978, p. 61.

${ }^{14}$ Dines, 1986, p. 47.

${ }^{15}$ G. Henry-Coston, citado por R. Lima (s/d; apresentada como coletânea de textos escritos entre 1943 e 1958 , p. 41). Lima comenta que considera esta caracterização um pouco romantizada, já que uma das principais características dos grandes jornais de sua época seria "a extrema separação das tarefas, a especialização, a divisão em setores autônomos e convergentes".

${ }_{16}$ Marx, Livro 1, Parte IV, Cap. 12, item 3.

${ }^{17}$ Perrot, 1992, p. 80.

${ }^{18}$ Albuquerque (2005).

${ }^{19}$ Norberto, s/d; p. 11. Na ficha de catalogação da Biblioteca da ABI, consta que o livro é do ano de 1953.

20 “Tribuna da Imprensa - Normas da Redação", s/d [Arquivo Carlos Lacerda, UnB]; presume-se que seja do final da década de 1940 ou dos primeiros anos da década de 1950.

${ }^{21}$ Nos manuais de orientação para a redação jornalística, é comum encontrar-se, até os dias atuais, a indicação que começou a aparecer, no Brasil, nos anos 1940: o texto deveria iniciar-se por um lead composto de respostas às seguintes questões: quem?, o quê?, onde?, quando?, por quê?, como? .

22 "Tribuna da Imprensa - Normas da Redação", s/d [Arquivo Carlos Lacerda, UnB].

${ }^{23}$ Publicado por M. H. Capelato e C. G. Mota, História da Folha de S. Paulo (1921-1981). SP, Impres, 1980, p. 99-100.

${ }^{24}$ Ramos, 1970, p. 171.

${ }^{25}$ Novo Manual de Redação, Folha de S. Paulo, 1992, p. 16.

${ }^{26}$ Idem.

${ }^{27}$ U.S. Government Printing Office, 1948. Preparada pelo National Roster of Scientific and Specialized Personnel of the War Manpower Commission para uso de programas educacionais das Forças Armadas do país. Arquivo Carlos Lacerda, UnB. Tradução da autora.

${ }^{28}$ Trata-se, respectivamente, de J. Hohenberg (1962) e F. Bond (1959).

29 É interessante observar que, a partir do início da década de 1990, os manuais escritos para a normatização do trabalho nas redações de jornais passaram a ser comercializados, atingindo números consideráveis de venda. Os primeiros foram o Manual Geral de Redação, da Folha de S.Paulo, e o Manual de Redação e Estilo, de O Estado de S. Paulo. Pode-se entender esse fato como um efeito da valorização da "escrita correta" como via para o reconhecimento social e a ascensão profissional, mas também como parte da promoção da imagem dos jornais, que, para Norberto, passava pelo vínculo entre correção formal e credibilidade.

${ }^{30}$ Tanto o Programa quanto as Normas de 1959 podem ser encontrados em M. H. Capelato e C. G. Mota (1980).

${ }^{31}$ Idem, p. 134.

${ }^{32}$ Beltrão., 1960, p. 160. Para o desenvolvimento desta questão, Beltrão se apóia em Octávio de la Suarée (1944).

${ }^{33}$ Idem, p. 163.

${ }^{34}$ Ataíde, 10/11/1957, apud Beltrão (1960, p. 163).

35 Agência Meridional de Notícias - Regulamento da Sucursal de Belo Horizonte, p. 3, s/d. Arquivo Carlos Lacerda, UnB. Há indicações de que seja da segunda metade dos anos 1940, quando Carlos Lacerda exerceu cargos de chefia nessa que foi durante aqueles anos a maior agência de notícias brasileira, pertencente a Assis Chateaubriand.

${ }^{36}$ Op. cit., p. 50.

37 Schudson, 2001 e Tuchman, 1992, p. 660-79.

${ }^{38}$ Rego, 1961, p. 72-4.

39 A influência dos Estados Unidos sobre a América Latina nesse período não foi casual, mas resultou de políticas de difusão de valores e práticas culturais e políticas, sobretudo durante o período da guerra fria. Fontes consultadas expõem a movimentação de jornalistas brasileiros e norte-americanos entre os dois países, em "missões" profissionais e culturais financiadas por organismos e associações sediadas nos Estados Unidos. 
${ }^{40}$ Ataíde, 1958, p. 146.

${ }^{41}$ Op. cit., p. 19.

42 Boletim da Federação Nacional de Jornalistas Profissionais, ano III, n. 3, julho de 1962. Arquivo Edgar Leuenroth, Unicamp.

${ }^{43}$ Boletim da Federação Nacional de Jornalistas Profissionais, ano IV, n. 5, set./out. de 1963. Arquivo Edgar Leuenroth, Unicamp.

${ }^{44}$ BOND, F. (op. cit.), p. VII. 